Images du travail, travail des images

\title{
Dans la blancheur
}

Gérard Mordillat

\section{OpenEdition}

Journals

Édition électronique

URL : http://journals.openedition.org/itti/348

DOI : $10.4000 /$ itti.348

\section{Éditeur}

Université de Poitiers

\section{Référence électronique}

Gérard Mordillat, «Dans la blancheur », Images du travail, travail des images [En ligne], 8 | 2020, mis en ligne le 01 février 2020, consulté le 14 avril 2021. URL : http://journals.openedition.org/itti/348 ; DOI : https://doi.org/10.4000/itti.348

Ce document a été généré automatiquement le 14 avril 2021.

Images du travail, travail des images 


\section{Dans la blancheur}

\section{Gérard Mordillat}

« Dans la blancheur des pages où la neige est l'image d'amours qu'on ne voit pas » Joë Bousquet

Image 1

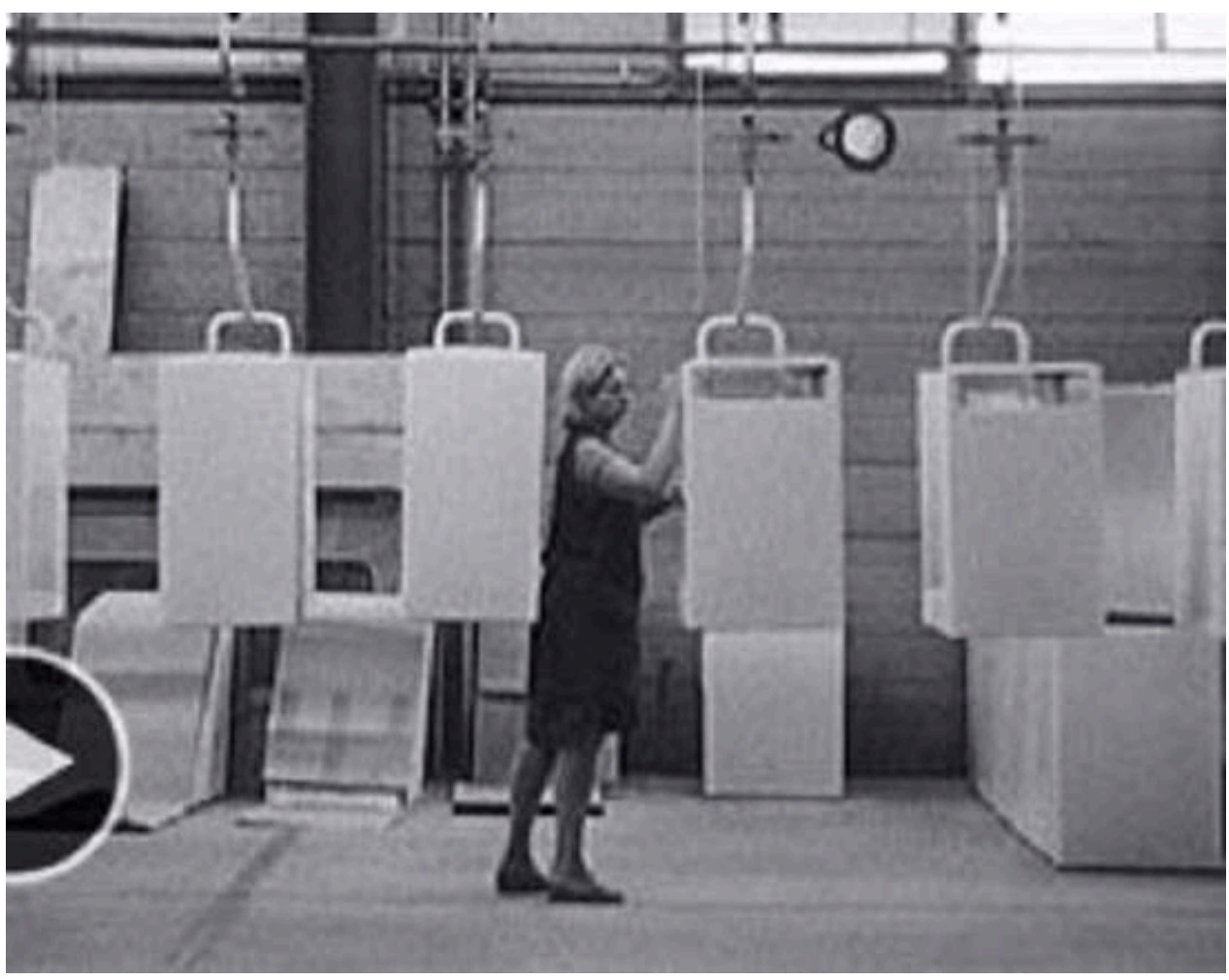

1 La scène est dans une usine du groupe Thomson où, en 1976, j'ai tourné La Voix de son maître, un film sur le discours patronal coréalisé avec Nicolas Philibert. Une femme travaille sur des caisses de machines à laver. Elle est chargée de faire des retouches là où l'émail n'est pas parfait. Et l'émail doit être parfait ! La chaîne l'entraîne à petits pas. Elle intervient sur la caisse avançant devant elle, poussée par celle de derrière comme 
par le bagage d'un voyageur impatient. Tout cela semble à la fois très lent et terriblement oppressant : ça avance, ça avance sans cesse, ça ne cesse jamais d'avancer, inexorable. Le travail est ici de l'espace et du temps. L'espace de travail de la femme n'est pas l'espace de l'atelier, c'est uniquement l'espace entre deux caisses. Elle n'a d'autre horizon que ce mur blanc d'émail où peut-être parfois apparaît son reflet. Par petites touches, elle écrit sa vie à l'encre sympathique sur cette page blanche. Elle raconte ce que nul autre qu'elle peut lire. Ce qu'elle vit, ce qu'elle ressent, ce qu'elle pense courant d'une caisse à l'autre. C'est une image de silence où l'imagination doit faire entendre le frottement de ses pieds sur le sol, le cliquetis mécanique de la chaîne, mais rien d'autre, pas même son souffle. C'est aussi une fixation du temps que la photographie cite. Du temps soudain arrêté alors que la photo prétend saisir le mouvement. On pense à l'image parfaitement nette d'un oiseau tué en plein vol. C'est de même nature. Une image parfaite qui est aussi parfaitement un leurre car cette image ne témoigne en rien de la réalité du travail de cette femme pas plus que l'oiseau photographié à l'instant même de sa mort ne témoigne de ce qui le tue. Ou - pour cette femme - si la photo témoigne de son travail, c'est par son inscription dans un espace où son corps (seule valeur sombre) trouve place dans le blanc qui la cerne. Le cadre devient alors son cadre de travail ; cadre qu'elle ne peut occuper que brièvement avant de se replacer entre les deux caisses de machine à laver, l'espace qui lui est assigné. Pressée par la chaîne, contrainte par le temps, cette femme n'est qu'un rouage anonyme de la machine économique. Cette photo drapée de lin blanc et de probité candide est une photo à charge.

\section{AUTEUR}

\section{GÉRARD MORDILLAT}

Né en 1949 dans le quartier de Belleville à Paris d'un père serrurier à la SNCF, Gérard Mordillat est à la fois poète, journaliste, romancier, réalisateur de documentaires et de fiction pour le petit comme le grand écran. On lui doit notamment le roman Vive la sociale !, le feuilleton télé Des vivants et des morts, un documentaire remarquable sur le patronat (La voix de son maître avec Nicolas Philibert) et, avec Jérôme Prieur, des séries documentaires télévisées diffusées sur Arte traitant du christianisme. 